as he deals with new evidence. Urquhart has reported flights of up to 2,000 miles by individual marked Monarch butterflies in North America: details of such flights, which are still awaited, and of the wind-systems encountered during them, may perhaps provide the first rigorous demonstration of long-range insect migration in the strict sense of Dr. Williams's definition.

R. C. RaINEY

\section{HYDROGEN ION CONCENTRATION AND ACTIVITY}

A Dictionary of $\mathrm{pH}$ Applications

By R. S. Evans. Pp. viii $+78+x v i i i$ (London: The Herbert Publishing Company, Ltd., 1957.) 10s. $6 d$. net.

The Book of $\mathrm{pH}$

A simple and complete Description of the Theory and the Practice of the Measurement of $p \mathrm{H}$ as applied to Science and Industry. By R. B. Webber. Pp. 111. (London: George Newnes, Ltd., 1957.) $30 s$. net.

THAT two books on the applications of $p \mathrm{H}$ to industrial processes should appear together is a remarkable coincidence. Mr. R. S. Evans's book is sponsored by W. G. Pye and Co., Ltd., of Cambridge, and Mr. R. B. Webber's by Tintometer, Ltd., of Salisbury. Both books are designed to impress the industrialist, who, incidentally, is assumed to have no chemical knowledge, of the great importance that $p \mathrm{H}$ data may be to him and yet how very simple it is to make $p \mathrm{H}$ measurements. In the first, it is stated that glass-electrode $p \mathrm{H}$ meters are rapidly replacing colorimetric methods, which are not even described, while in the second, colorimetric and electrometric methods are very simply discussed, but it is emphasized that colorimetric methods are very much easier to operate, especially if use is made of the Lovibond comparator and Nessleriser in conjunction with permanent colour standards (of glass) which correspond with the colours of indicators at specified $p \mathbf{H}$ values, and which are mounted in a rotating disk to facilitate comparison. To estimate the $p \mathrm{H}$ of unbuffered, or poorly buffered, solutions, when it is essential to use as low a concentration of indicator as possible, the Nessleriser is used. In this method it is assumed that the effect of the $p \mathrm{H}$ of the indicator itself is rendered negligible. It would have been better if the isohydric indicator method had been given, but perhaps the reason for its omission is to be found in the assertion made on p. 81 that "the operators need not be particularly intelligent or skilful" to carry out colorimetric determinations.

Explaining the meaning of $p \mathrm{H}$ to the uninitiated is obviously something of a problem. Evans is content to leave the problem by saying that the $p H$ value "may loosely be defined as a measure of acidity or alkalinity", whereas Webber starts off by stating that "the concept of $p \mathrm{H}$ is fundamentally very simple" and likens the $p H$ scale to the centigrade scale of temperature, each number of the $p \mathbf{H}$ scale having "an exact meaning". Later, he declares that "the $p H$ story is not an over-simple one". In the middle of the book he gives the mathematical expres. sion which relates $p \mathrm{H}$ with hydrogen ion concentration, but towards the end he attempts to explain that it would be better to substitute activity for concentration. It must be comforting to the reader to be told that whichever view is accepted it will only make a difference in the observed $p \mathbf{H}$ value, within the $p \mathrm{H}$ range $2-12$, of $\pm 0.02 p \mathrm{H}$ unit.

Webber includes a couple of pages on measuring the hydrogen ion activity of non-aqueous solutions and refers to the $c \mathrm{G}$ scale which $\mathrm{J}$. $\mathrm{B}$. Conant introduced many years ago but which has not been seriously regarded. Such a discussion might be considered to be out of place in a book of this type.

Both volumes might be considered to have fulfilled a need, but that of Webber has done so more effectively.

H. T. S. Britton

\section{APPLIED ACOUSTICS}

Acoustics, Noise, and Buildings

By P. H. Parkin and H. R. Humphreys. Pp. 331. (London: Faber and Faber, Ltd., 1958.) 70s. net.

TN post-war Britain classical physics has been much neglected because of the great attractions of nuclear physics. Consequently, activity in Great Britain on the subject of acoustics is on a very small scale, although slightly more is now done than before the War, when the subject was practically ignored. In the United States and on the continent of Europe, on the other hand, much more work is done, and considerable effort goes into research and investigation. It is therefore not surprising that, although several text-books have been published in Europe or in America and some of the European books have been translated into English, the last important book was "Acoustics" by the late Alexander Wood, published in 1940. Messrs. Parkin and Humphreys are therefore to be congratulated on writing the present volume, which fills a long-felt want.

This book is not intended to be a text-book but a survey of the subject for those not qualified in physics, such as architects, engineers and others who may be interested in acquiring a reasonable knowledge. The first two chapters on the "Nature of Sound" and "The Behaviour of Sound in Rooms" are in elementary terms to act as an introduction to the subject. Chapter 3 describes "The Design of Rooms for Speech" and should be of great value to individuals interested in the improvement of the acoustics of theatres, lecture rooms, classrooms and similar buildings. Chapter 4 describes a much more specialized field, "The Design of Rooms for Music". The description of the various factors affecting design is very lucid, and most of the difficulties are described in considerable detail. Greater emphasis might, however, with advantage have been placed on the fact that the final criterion for such rooms is æsthetic and that personal opinion plays a large part in the final judgment. Chapter 5, "The Design of Studios", describes the design of studios for broadcasting, which is a very specialized field indeed.

Another feature of post-war civilization seems to be the absence of the orator capable of addressing a large audience without assistance from electroacoustic devices. 'Public address' has consequently become firmly established even in quite small auditoria. Chapter 6, "The Design of High Quality Speech-Reinforcement Systems", is therefore a very valuable contribution and is particularly interesting for its description of the methods used for speech- 